\title{
Acetylcholine mechanism of action to enhance tolerance to salt stress in Nicotiana benthamiana
}

\author{
C. QIN", Y.Y. SU*, B.S. LI*, Y.Q. CHENG ${ }^{*}$, C.C. WEI* ${ }^{* *}$ S. YUAN ${ }^{* * *}$, N. AHMED ${ }^{\#}$, M. ASHRAF"\#, \\ and L.X. ZHANG ${ }^{*+}$
}

College of Life Sciences, Northwest A\&F University, 712100 Yangling, China*

Tobacco Science Institution of Shaanxi Province, 710061 Xi'an, China ${ }^{* *}$

Technology Center of China Tobacco Shaanxi Industrial Co., Ltd., 710065 Xi'an, China $^{* * *}$

Department of Botany, Mohi-Ud-Din Islamic University, 12080 Tarar Khal, Pakistan\#

Institute of Molecular Biology and Biotechnology, The University of Lahore, 54590 Lahore, Pakistan\#

\begin{abstract}
Acetylcholine $(\mathrm{ACh})$ is one of the important neurotransmitters, involved in signal transduction function in human and animal brain. However, the influence of ACh treatment on salt-stress tolerance in plants is yet unknown. Salt stress caused a reduction in gas-exchange parameters, chlorophyll content, antioxidant enzyme activities, and leaf relative water content of Nicotiana benthamiana plants. However, the above inhibitions could be significantly alleviated by application of leaf spray or root application of ACh. Exogenous ACh reduced the accumulation of malondialdehyde by enhancing activities of antioxidant enzymes such as peroxidase and superoxide dismutase. In addition, enhanced accumulation of organic osmolytes including soluble sugars and proline possibly regulated the signal mechanisms related to stress. Application of ACh could also improve gas-exchange parameters and photosynthetic pigment accumulation in leaves of salt-stressed plants. These effects of ACh were beneficial for maintaining better water status in plants, the concentration of $10 \mu \mathrm{M}$ ACh applied both in the form of leaf spray or root application was the most effective. Therefore, our findings provided a stronger evidence for a physiological role of ACh and its potential use at optimal concentration by leaf or root application to alleviate damage caused by salt-stress in plants.
\end{abstract}

Additional key words: antioxidant system; leaf gas exchange; reactive oxygen species; salinity stress.

\section{Introduction}

Salinity is a premier environmental cue that restricts growth and quality of agricultural crops (Zhu 2003, Ismail and Horie 2017), because it causes multiple effects in plants such as ionic stress, osmotic stress, nutritional disorder occurring individually or jointly (Ashraf and Harris 2004, Munns and Gilliham 2015). Several reports exist in the literature that show the differences in photosynthetic characteristics of salinity-tolerant $v s$. sensitive plants (Chaves et al. 2009, Sarkar et al. 2013, Feng et al. 2014). A variety of physio-biochemical processes including primarily photosynthesis are drastically impaired by unfavorable conditions (Lahive et al. 2018, Zlobin et al. 2019). These include modification of characteristics of the photosynthetic apparatus, and changes in chlorophyll (Chl) contents (Bae et al. 2012). Chl is an essential component of the process of photosynthesis and it plays a critical role in plant development (Zhen et al. 2014). Membrane lipid peroxidation occurs as a consequence of the stress-induced cellular damage produced by the generation of reactive oxygen species (García et al. 2016). Therefore, antioxidant defense enzyme activities and contents of compatible osmolytes, such as proline and soluble sugars, undergo changes in plants exposed to saline environment (Ashraf and Foolad 2007, Miller et al. 2010, Parvaiz et al. 2016).

To achieve improved plant tolerance to salinity and hence enhanced crop productivity, application of exogenous substances has been used widely (Ahmad et al. 2016, Li et al. 2016, 2017a). In the past few years, research on function of animal neurotransmitter in stress tolerance has obtained much interest. For example, melatonin plays an important role in plant defense against stressful cues, such as drought, salinity, radiation, and chemical

$\overline{\text { Received }} 2$ July 2018, accepted 28 November 2018.

${ }^{+}$Corresponding author; e-mail: zhanglixin@nwsuaf.edu.cn

Abbreviations: $\mathrm{ACh}$ - acetylcholine; $C_{\mathrm{i}}$ - intercellular $\mathrm{CO}_{2}$ concentration; $\mathrm{Chl}$ - chlorophyll; DM - dry mass; $E$ - transpiration rate; FM - fresh mass; $g_{\mathrm{s}}$ - stomatal conductance; LRWC - leaf relative water content; MDA - malondialdehyde content; $P_{\mathrm{N}}-$ net photosynthetic rate; POD - peroxidase; ROS - reactive oxygen species; SOD - superoxide dismutase; SS - soluble sugars; TBA - thiobarbituric acid; TCA - trichloroacetic acid.

Acknowledgements: The authors gratefully acknowledge the financial support for this study through the National Key Research and Development Program of China (No. 2017YFE0114000), Sci-tec Project of Shaanxi Province Company of China National Tobacco Corporation (SXYC-2016-KJ-02), and Sci-tech Project of China Tobacco Shaanxi Industrial Co., Ltd. (JS-FW-2016-001). 
stresses (Zhang et al. 2015). Acetylcholine (ACh) is one of the most exemplary neurotransmitters (Wessler et al. 2001). It was first revealed in non-animal organisms (Ewins 1914). Since then, it has been found in all types of plants as well as in bacteria and fungi (Fluck and Jaffe 1976). It has also been detected in non-neural tissues, e.g., sperms, erythrocytes, and placental cells (Sastry and Sadavongvivad 1978). Sagane et al. (2005) demonstrated that the acetylcholinesterase (AChE) family cloned from maize entails a unique AChE family that is widely found in the plant kingdom. Therefore, the presence of ACh and its related molecules might play a role in plant response to environmental stimuli. After that, Yamamoto et al. (2011) reported a beneficial role of $\mathrm{AChE}$ in maize for resistance to heat stress mediated by overexpression of maize AChE in transformed tobacco (Nicotiana benthamiana) plants relative to that in nontransformed ones. Research on the effects of ACh on several growth and developmental phenomena in plants have been conducted (Tretyn and Kendrick 1991). Sugiyama and Tezuka (2011) revealed that the emergence and elongation of lateral roots of Raphanus sativus could be regulated by $1 \mathrm{nM}$ ACh. Braga et al. (2017) showed that the growth and dry matter accumulation were promoted by ACh under osmotic stress in soybean seedlings. However, relevant information about the possible regulatory effect of $\mathrm{ACh}$ on tolerance to salt stress in plants is still lacking.

Nicotiana benthamiana, with a short growth cycle, is an important model plant and has special significance in the field of genetics, development, and transgenesis (Wang et al. 2015). The aim of the study is to understand if ACh is involved in salt tolerance of Nicotiana benthamiana. We determined whether ACh treatment could alleviate salt stress by regulating main physiological metabolism of Nicotiana benthamiana seedlings. For this purpose, regulation of gas-exchange characteristics, antioxidant defense system and contents of some key organic osmolytes in salt-stressed Nicotiana benthamiana plants fed with ACh was appraised.

\section{Materials and methods}

Plant material: Nicotiana benthamiana plants at the sixleaf stage were used in this study. Seeds were germinated in vermiculite and nutritional soil. The plants of uniform size were transplanted into plastic culture pots $(245 \times$ $170 \times 75 \mathrm{~mm}$; four plants per pot) containing $1.5 \mathrm{~L}$ of $1 / 2$ strength Hoagland's nutrient solution. The experiment was conducted in a growth chamber ( $R X Z-380 C-L E D$, ZheJiang, China) at the Northwest A\&F University, Yangling, Shaanxi, P. R. China. The day/night air temperatures were $28 / 25^{\circ} \mathrm{C}$ with 16 -h day, and relative humidity of $60-70 \%$.

Pre-cultivation: Seedlings were treated with 1, 10, 50, and $100 \mu \mathrm{M}$ ACh solution in the form of leaf spray or root application. Acetylcholine chloride was procured from Sigma-Aldrich ( $\geq 99 \%$, St. Louis, MO, USA). Foliar spraying ensured that both sides of the leaves remained wet. This process occurred in the morning and in the afternoon. Root application was performed by applying different concentrations of ACh into solution.

Leaf discs and in vitro test: Leaf discs of $15 \mathrm{~mm}$ in diameter were cut from healthy Nicotiana benthamiana seedlings. They were immediately placed in Petri dishes each filled with $20 \mathrm{~mL}$ of either distilled water (C), or 150 $\mathrm{mM}$ of $\mathrm{NaCl}$ solution $(\mathrm{S})$, or $150 \mathrm{mM} \mathrm{NaCl}+10 \mu \mathrm{M}$ ACh (S-A 10), or $150 \mathrm{mM} \mathrm{NaCl}+100 \mu \mathrm{M}$ ACh (S-A 100). All the treatments were subjected to $25^{\circ} \mathrm{C}$ room temperature. Photographs were taken after $72 \mathrm{~h}$ of the treatment.

Salt-stress treatment was started by adding an amount of $\mathrm{NaCl}$ equivalent to $150 \mathrm{mM}$ to the nutrient medium in the absence or presence of ACh. Finally, in the main experiment, salt stress treatment and $\mathrm{ACh}$ applications were performed as follows:

\begin{tabular}{lll}
\hline Treatment & Leaf spray & Root application \\
\hline $\mathrm{C}$ & $\mathrm{H}_{2} \mathrm{O}$ & $\mathrm{H}_{2} \mathrm{O}$ \\
$\mathrm{S}$ & $\mathrm{H}_{2} \mathrm{O}$ & $150 \mathrm{mM} \mathrm{NaCl}$ \\
R-1 & $\mathrm{H}_{2} \mathrm{O}$ & $1 \mu \mathrm{M} \mathrm{ACh}+150 \mathrm{mM} \mathrm{NaCl}$ \\
R-10 & $\mathrm{H}_{2} \mathrm{O}$ & $10 \mu \mathrm{M} \mathrm{ACh}+150 \mathrm{mM} \mathrm{NaCl}$ \\
R-50 & $\mathrm{H}_{2} \mathrm{O}$ & $50 \mu \mathrm{M} \mathrm{ACh}+150 \mathrm{mM} \mathrm{NaCl}$ \\
R-100 & $\mathrm{H}_{2} \mathrm{O}$ & $100 \mu \mathrm{M} \mathrm{ACh}+150 \mathrm{mM} \mathrm{NaCl}$ \\
L-1 & $1 \mu \mathrm{M}$ Ach & $150 \mathrm{mM} \mathrm{NaCl}$ \\
L-10 & $10 \mu \mathrm{M}$ ACh & $150 \mathrm{mM} \mathrm{NaCl}$ \\
L-50 & $50 \mu \mathrm{M}$ ACh & $150 \mathrm{mM} \mathrm{NaCl}$ \\
L-100 & $100 \mu \mathrm{M} \mathrm{ACh}$ & $150 \mathrm{mM} \mathrm{NaCl}$ \\
\hline
\end{tabular}

Both the application of $\mathrm{NaCl}$ and $\mathrm{ACh}$ were done at the same time (Fig. 1). Then, after $15 \mathrm{~d}$ of treatments, the second upper fully developed leaves of Nicotiana benthamiana plants were taken, instantly placed in liquid

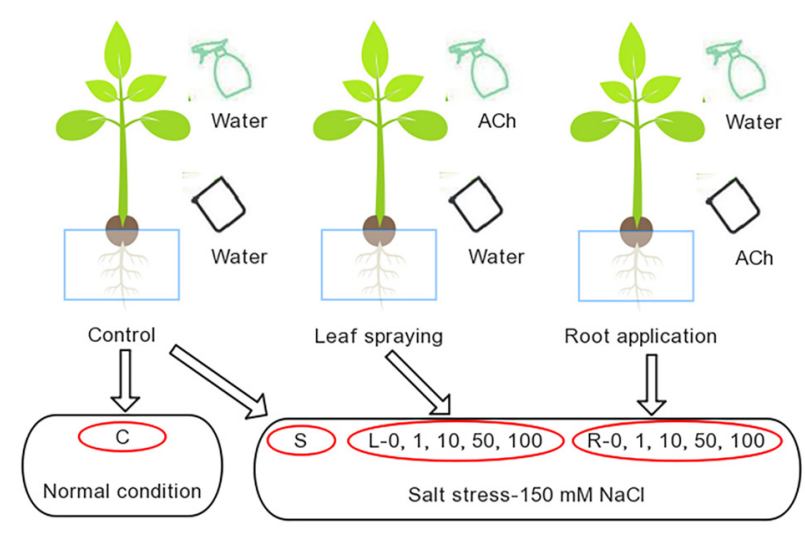

Fig. 1. A schematic diagram of leaf spraying or root application with acetylcholine $(\mathrm{ACh})$ and salt-stress treatments. $\mathrm{C}$ - plants grown under normal conditions for $15 \mathrm{~d}$ after supplying water through roots or as foliar spray; $\mathrm{S}$ - plants grown at $150 \mathrm{mM}$ $\mathrm{NaCl}$ for $15 \mathrm{~d}$ after supplying water through roots or as foliar spray. $\mathrm{L}$ - plants grown at $150 \mathrm{mM} \mathrm{NaCl}$ for $15 \mathrm{~d}$ after supplying ACh $(1,10,50$, and $100 \mu \mathrm{M})$ to leaves; $\mathrm{R}$ - plants grown at $150 \mathrm{mM} \mathrm{NaCl}$ for $15 \mathrm{~d}$ after supplying $\mathrm{ACh}(1,10,50$, and $100 \mu \mathrm{M})$ to roots. 
$\mathrm{N}_{2}$, and then transferred to a freezer at $-80^{\circ} \mathrm{C}$ until further analytical procedures. Within each treatment there were three biological replicates.

Chl content: Leaf samples (each $0.1 \mathrm{~g}$ ) were extracted in $15 \mathrm{~mL}$ of $80 \%$ acetone using a shaker overnight at room temperature. After centrifugation at $5,000 \times \mathrm{g}$ for $5 \mathrm{~min}$, the supernatant obtained was checked for absorbance at two wavelengths, i.e., 645 and $663 \mathrm{~nm}$, using a spectrophotometer (UV-2800, Shimadzu, Kyoto, Japan). Total Chl concentration was estimated following the formula developed by Gao et al. (2016): $\mathrm{Chl}(a+b)=20.29 \times \mathrm{A}_{645}+$ $8.05 \times \mathrm{A}_{663}$. Simultaneously, the Chl content of seedlings was measured with a chlorophyll meter (SPAD-502, Minolta, Japan).

Leaf gas-exchange parameters: Fully expanded leaves from each plant were used to estimate net photosynthetic rate $\left(P_{\mathrm{N}}\right)$, transpiration rate $(E)$, stomatal conductance $\left(g_{\mathrm{s}}\right)$, and intercellular $\mathrm{CO}_{2}$ concentration $\left(C_{\mathrm{i}}\right)$ using a $L I-6400$ photosynthesis system (LI-COR Inc., Lincoln, NE, USA) during the period of 9:00-11:00 h. The instrument was set at a light intensity of $1,000 \mu \mathrm{mol}$ (photon) $\mathrm{m}^{-2} \mathrm{~s}^{-1}$ and airflow rate of $500 \mu \mathrm{mol} \mathrm{s}^{-1}$. The cuvette $\mathrm{CO}_{2}$ was adjusted at $400 \mu \mathrm{mol}\left(\mathrm{CO}_{2}\right) \mathrm{mol}^{-1}$ (air) (Gao 2006).

Proline content: Fresh leaf sample was used for the following procedure described by Bates et al. (1973). To a 0.5 -g leaf sample, $5 \mathrm{~mL}$ of $3 \%$ sulfosalicylic acid were added; the mixture was kept in boiling water for $10 \mathrm{~min}$. The supernatant (each $2.0 \mathrm{~mL}$ ) was mixed with $2 \mathrm{~mL}$ of acetic acid and $3 \mathrm{~mL}$ of $2.5 \%$ ninhydrin solution. The mixture was placed in hot water for $40 \mathrm{~min}$, and then $4 \mathrm{~mL}$ of methyl benzene were added. The optical density (OD) of the reacted mixture was noted at $520 \mathrm{~nm}(U V-2800$, Shimadzu, Kyoto, Japan). Proline content was expressed as $\mu \mathrm{g} \mathrm{g}^{-1}(\mathrm{FM})$.

Soluble sugar content: Dried leaf was used for assay following Spiro (1966). Dry leaf sample (each $0.5 \mathrm{~g}$ ) was transferred to a glass vial containing $10 \mathrm{~mL}$ of $80 \%(\mathrm{v} / \mathrm{v})$ ethanol and subjected to $80^{\circ} \mathrm{C}$ for $30 \mathrm{~min}$. The mixture was centrifuged at 3,500 $\times g$ after cooling. The extract was filtered and diluted to $20 \mathrm{~mL}$ using $80 \%$ (v/v) ethanol. The supernatant was added to $3 \mathrm{~mL}$ (final volume) of assay media containing $1.08 \mathrm{M} \mathrm{H}_{2} \mathrm{SO}_{4}, 1.09 \mathrm{mM}$ thiourea, and $2.1 \mathrm{mM}$ anthrone. The sample was subjected to $100^{\circ} \mathrm{C}$ for $10 \mathrm{~min}$ and OD was recorded at $620 \mathrm{~nm}(U V-2800$, Shimadzu, Kyoto, Japan). A calibration curve drawn using pure D-glucose was prepared to calculate the concentrations of soluble sugars in all samples.

Enzyme extracts and assays: Fresh leaf sample (each $0.2 \mathrm{~g}$ ) was homogenized using a pestle and mortar with $0.05 \mathrm{M}$ sodium phosphate buffer $(\mathrm{pH} 7.5)$. The mixture was subjected to centrifugation for $20 \mathrm{~min}$ at $10,000 \times \mathrm{g}$. The supernatant was used for estimating the activities of superoxide dismutase (SOD, EC 1.15.1.1) and peroxidase (POD, EC 1.11.1.7). The above steps were carried out at $4^{\circ} \mathrm{C}$. The SOD activity was appraised as described by Gao
(2006). The reaction mixture contained $50 \mathrm{mM} \mathrm{Na}_{2} \mathrm{HPO}_{4}$ $\mathrm{NaH}_{2} \mathrm{PO}_{4}$ buffer, methionine, nitroblue tetrazolium salt (NBT), EDTA-Na 2 , riboflavin, and $0.3 \mathrm{~mL}$ of the enzyme extract. All treated samples were stirred under darkness, and then exposed to fluorescent lamps [160 $\mu \mathrm{mol}($ photon) $\mathrm{m}^{-2} \mathrm{~s}^{-1}$ ] for $5 \mathrm{~min}$; the reaction temperature was controlled between 25 and $35^{\circ} \mathrm{C}$. The reacted mixtures were read at $560 \mathrm{~nm}$ using a spectrophotometer (UV-2800, Shimadzu, Kyoto, Japan) against a blank. One unit of SOD was considered as the amount of enzyme inhibiting 50\% of NBT reduction. The SOD activity was expessed as $\mathrm{U} \mathrm{g}^{-1}(\mathrm{FM}) \mathrm{h}^{-1}$.

The POD activity was assayed following Gao (2006). Reaction solution $(4 \mathrm{~mL})$ comprised $0.1 \mathrm{~mol} \mathrm{~L}^{-1}$ sodium phosphate buffer ( $\mathrm{pH} 7.8), 28 \mu \mathrm{L}$ of guaiacol $(10 \mathrm{mM})$, $30 \% \mathrm{H}_{2} \mathrm{O}_{2}$, and $1 \mathrm{~mL}$ of the enzyme extract. Changes in the OD of the reaction solution at $470 \mathrm{~nm}$ were recorded using a spectrophotometer (UV-2800, Shimadzu, Kyoto, Japan) every $1 \mathrm{~min}$. The POD activity was expressed as $\mathrm{Ug}^{-1}(\mathrm{FM}) \mathrm{min}^{-1}$.

Lipid peroxidation was assayed by quantifying the malondialdehyde (MDA) contents using the method of Hodges et al. (1999). The leaf sample (0.5 g) was triturated in $8 \mathrm{~mL}$ of $0.1 \%(\mathrm{w} / \mathrm{v})$ trichloroacetic acid (TCA) and subjected to centrifugation for $20 \mathrm{~min}$ at $1,000 \times \mathrm{g}$. To the suspension, $1.5 \mathrm{~mL}$ of reaction solution $(0.5 \%$ thiobarbituric acid solution (TBA) with 5\% TCA) was added and then placed in a water bath. The mixture was centrifuged for $10 \mathrm{~min}$ at $7,888 \times \mathrm{g}$. Absorbance measurements were obtained at 532 and $660 \mathrm{~nm}(U V-2800$, Shimadzu, Kyoto, Japan). Following formula was employed to calculate the MDA content: $6.45 \times\left(\mathrm{A}_{532}-\mathrm{A}_{600}\right)-0.56 \times \mathrm{A}_{450}$.

Leaf relative water content (LRWC) was assessed following Gao et al. (2016). The leaves were detached from the seedlings and their fresh mass (FM) measured instantly. Thereafter, the turgid mass (TM) was appraised after placing the leaves in deionized distilled water overnight at $4^{\circ} \mathrm{C}$. Finally, the leaves were oven-dried at $80^{\circ} \mathrm{C}$ for $48 \mathrm{~h}$ and the dry mass (DM) was recorded. LRWC [\%] was calculated according to the following formula: LRWC = $[(\mathrm{FM}-\mathrm{DM}) /(\mathrm{TM}-\mathrm{DM})] \times 100$.

Statistical analysis: Statistical significance of the treatments was evaluated by analysis of variance (ANOVA) followed by the mean separation by Duncan's multiple range test (DMRT) using SPSS 17.0. The results represent mean \pm standard error (SD) of three replicates for each treatment $(P \leq 0.05)$.

\section{Results}

Chl content: An obvious chlorosis was observed in salt-stressed Nicotiana benthamiana caused by reduced accumulation of $\mathrm{Chl}$ (Fig. 2). The ACh application was found to be effective in alleviating this salt-stressinduced leaf chlorosis by increasing the Chl content in leaf discs. However, the most promising effect was found at the lower concentration of ACh $(10 \mu \mathrm{M})$. In order to 


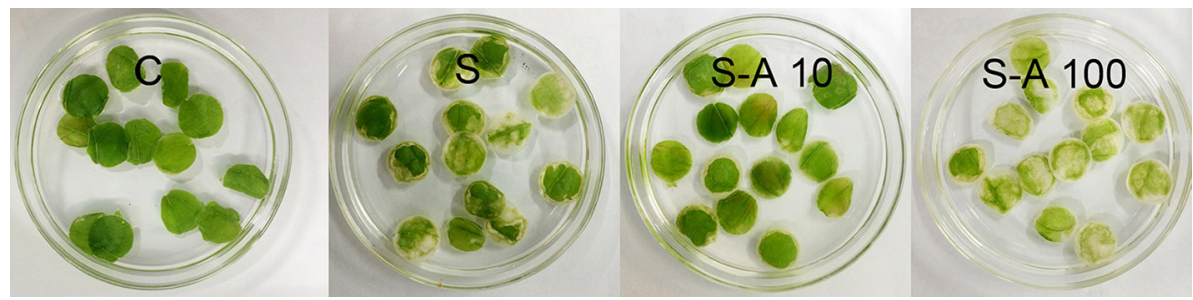

Fig. 2. Changes in green color intensity in leaf discs of Nicotiana benthamiana plants. $\mathrm{C}-$ water, $\mathrm{S}-$ salt stress $(150 \mathrm{mM} \mathrm{NaCl}), \mathrm{S}-\mathrm{A} 10-150$ $\mathrm{mM} \mathrm{NaCl}+10 \mu \mathrm{M}$ acetylcholine (ACh), S-A $100-150 \mathrm{mM} \mathrm{NaCl}$ $+100 \mu \mathrm{M}$ ACh. Photographs were taken after $72 \mathrm{~h}$ of discs incubation in different solutions.

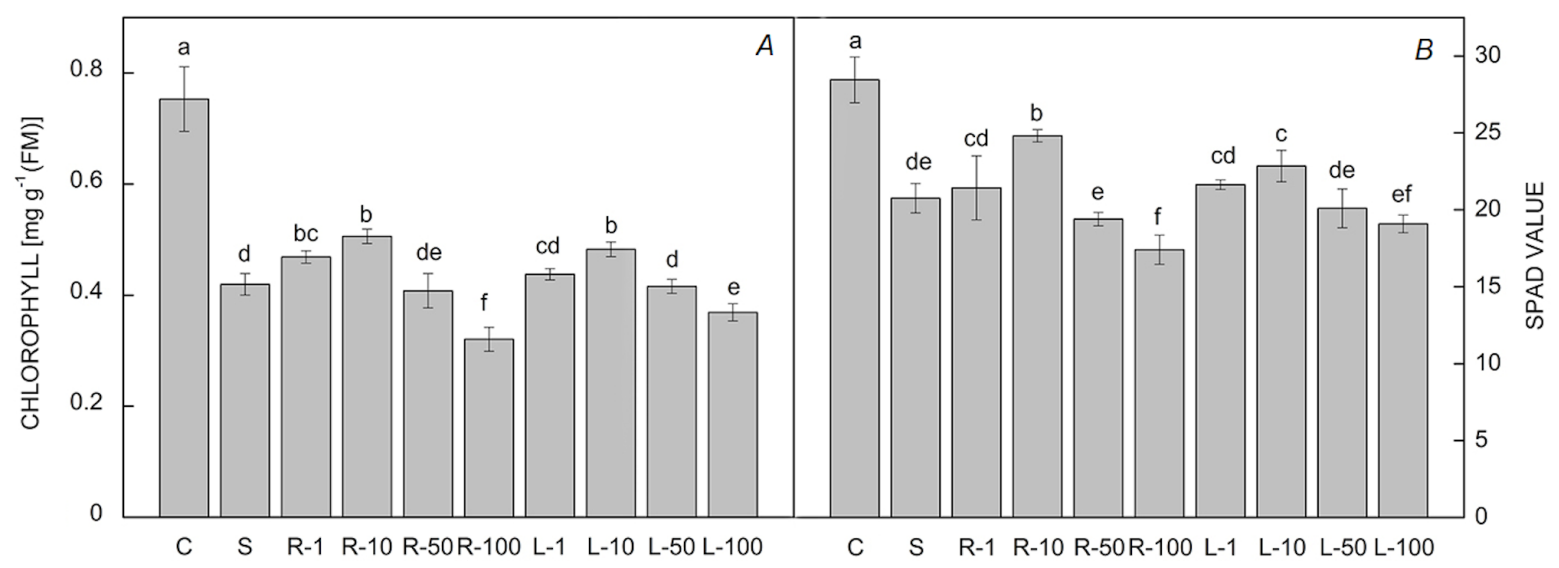

Fig. 3. Effects of the root application (R) or leaf spraying (L) with 1, 10, 50, and $100 \mu \mathrm{M}$ acetylcholine (ACh) on the chlorophyll content $(A)$ and SPAD value $(B)$ of 15-d-old Nicotiana benthamiana plants grown in 1/2 Hoagland solution with or without $150 \mathrm{mM} \mathrm{NaCl}$. Data are the means $\pm \mathrm{SD}, n=3$. Different letters in the same column indicate significant difference between treatments at $p \leq 0.05$ using DMRT.

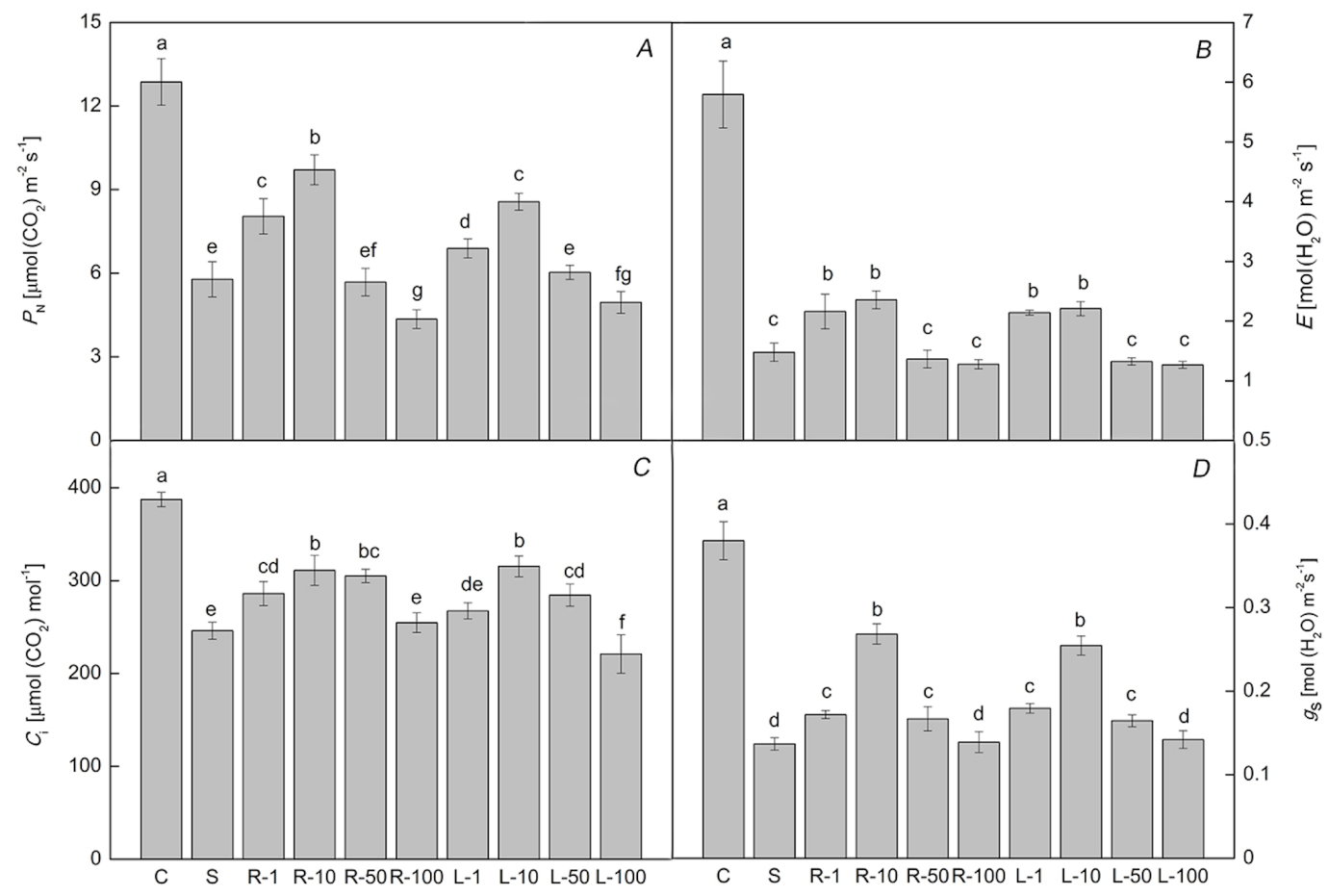

Fig. 4. Effects of the root application (R) or leaf spraying (L) with 1, 10, 50, and $100 \mu \mathrm{M}$ acetylcholine (ACh) on gas-exchange parameters of 15-d-old Nicotiana benthamiana plants grown in 1/2 Hoagland solution with or without $150 \mathrm{mM} \mathrm{NaCl}$. $(A) P_{\mathrm{N}}-$ net photosynthesis rate, $(B) E$ - transpiration rate, $(C) C_{\mathrm{i}}$ - intercellular $\mathrm{CO}_{2}$ concentration, and $(D) g_{\mathrm{s}}-$ stomatal conductance. Data are the means $\pm \mathrm{SD}, n=3$. Different letters in the same column indicate significant difference between treatments at $p \leq 0.05$ using DMRT. 
examine whether ACh could alleviate the salinity-induced impairment in Chl anabolism, measurement of the $\mathrm{Chl}$ content either spectrophotometrically or SPAD was carried out. The results showed that Chl contents of leaves decreased markedly under salt stress. (Fig. 3). However, the Chl content was enhanced significantly by 15 and $20.6 \%$ in L-10 and R-10, respectively, compared with that under the $\mathrm{S}$ treatment. The $\mathrm{Chl}$ content decreased when the ACh concentration was higher than $50 \mu \mathrm{M}$. The lowest Chl content was found in R-100 and L-100. A similar trend was observed in SPAD values.

Photosynthetic gas-exchange parameters: $P_{\mathrm{N}}, g_{\mathrm{s}}, C_{\mathrm{i}}$, and $E$ decreased significantly by $\mathrm{S}$ in comparison with $\mathrm{C}$ treatment (Fig. 4). With the increase in the concentration, either root application (R) or foliar spraying treatments (L) with ACh showed first an increasing and then a decreasing effect. The $P_{\mathrm{N}}$ increased significantly by 48.1 and $67.9 \%$ in L-10 and R-10, respectively, compared with that in $\mathrm{S}$ (Fig. 4A). The highest concentration of ACh $(100 \mu \mathrm{M})$ did not show an alleviating effect of on photosynthetic rate of salt-stressed plants. $P_{\mathrm{N}}$ was the lowest at L-100 and R-100. A similar effect of ACh was observed on $E$ with the most effective concentration being $10 \mu \mathrm{M}$ (Fig. $4 B$ ). $C_{\mathrm{i}}$ was high when the exogenous ACh concentration was lower than $50 \mu \mathrm{M}$, but it consistently decreased when the ACh concentration was over $50 \mu \mathrm{M}$. $C_{\mathrm{i}}$ was reduced by $22.7 \%$ in L-100 and no reduction was found in R-100 compared with that under S treatment (Fig. 4C). Thus, exogenous application of $10 \mu \mathrm{M}$ of ACh markedly improved $g_{s}$ of the seedlings 1.96 and 1.86 times in R-10 and L-10, respectively, compared with that at $\mathrm{S}$ treatment (Fig. 4D).

MDA accumulation: Salt stress (S) resulted in a significant increase of the MDA accumulation as compared to that in the $\mathrm{C}$ treatment. However, both root application and leaf spraying with 1 and $10 \mu \mathrm{M}$ ACh decreased the MDA content significantly (Fig. $5 A$ ). The MDA content at R-10 and L-10 decreased by 44.6 and $44.5 \%$, respectively, compared with that at $\mathrm{S}$ (Fig. $5 A$ ).

Activities of SOD and POD: In this study, the saltstressed seedlings (S) had higher SOD and POD activities compared with control (C) (Fig. 5B,C). However, an increase in SOD and POD activities was observed in saltstressed plants after the application of ACh (both root application and leaf spray). R-10 and L-10 treatments further enhanced the SOD activities by 23.7 and $37.2 \%$, respectively, compared to $\mathrm{S}$ plants. Similarly, R-10 and L-10 treatments also further enhanced the POD activities by 27.2 and $54.2 \%$, respectively, compared to plants exposed to salt stress alone (Fig. 5B,C).

Proline accumulation: Proline content was significantly higher (approximately 3.43 fold) in $\mathrm{S}$ than that in $\mathrm{C}$ treatment (Fig. 6A). Varying exogenous concentrations of ACh applied both by leaf spraying or root application could enhance proline accumulation under salt stress. The highest content of proline was observed in R-10 and L-50,

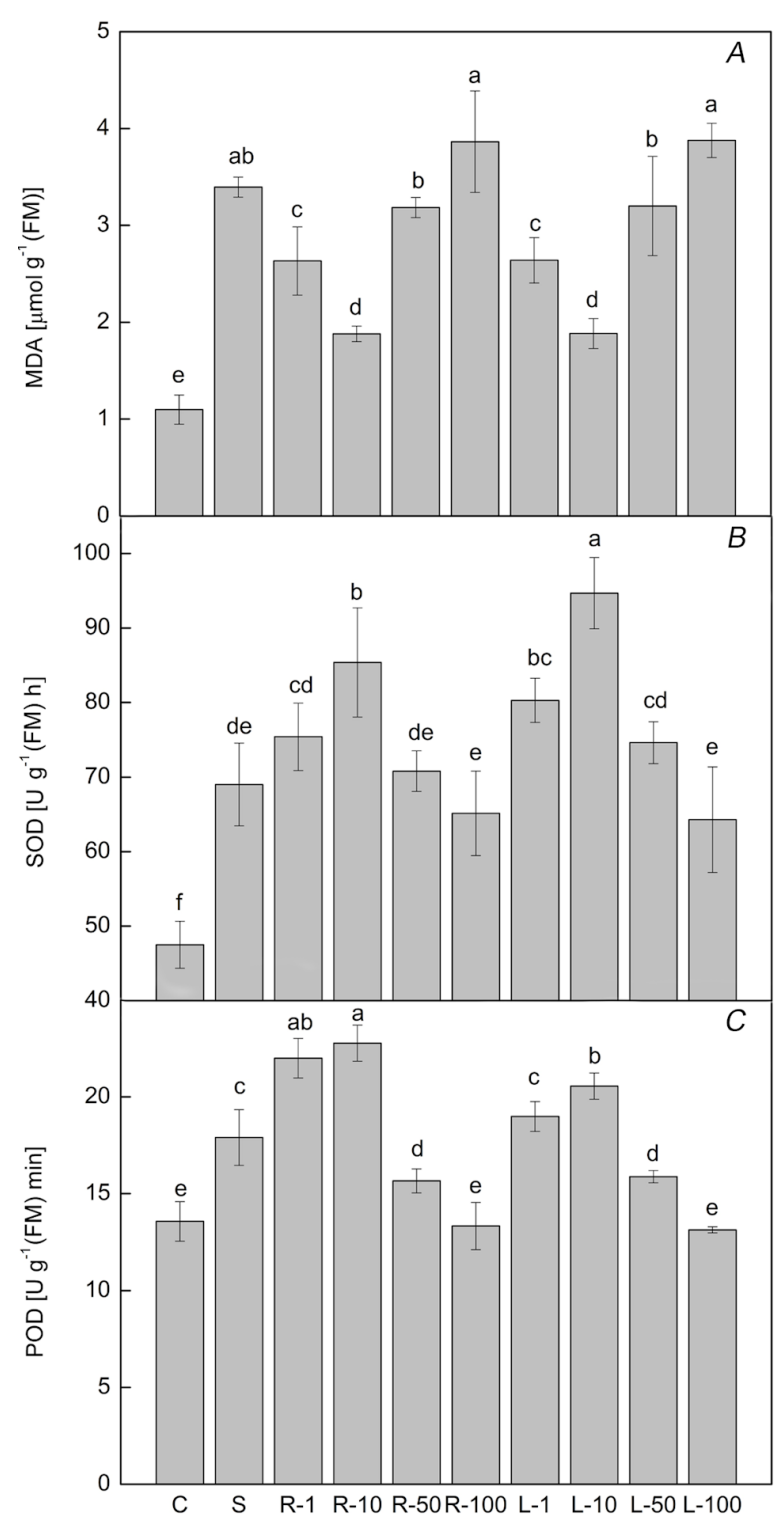

Fig. 5. Effects of the root application (R) or leaf spraying (L) with $1,10,50$, and $100 \mu \mathrm{M}$ acetylcholine (ACh) on malondialdehyde (MDA) content $(A)$, superoxide dismutase (SOD) activity $(B)$, and peroxidase (POD) activity $(C)$ of 15-d-old Nicotiana benthamiana plants grown in $1 / 2$ Hoagland solution with or without $150 \mathrm{mM} \mathrm{NaCl}$. Data are the means $\pm \mathrm{SD}, n=3$. Different letters in the same column indicate significant difference between treatments at $p \leq 0.05$ using DMRT.

which showed 68.3 and $51.3 \%$ increase compared to that in S treatment, respectively.

Soluble sugar accumulation: The $\mathrm{S}$ treatment significantly increased soluble sugar accumulation in leaves compared with $\mathrm{C}$ treatment (Fig. 6B). The maximum content of soluble sugars was recorded in R-10 and L-10, it was 33.9 and $32.4 \%$ higher compared to $\mathrm{S}$ treatment, respectively. However, the high concentration of ACh (R-100 and $\mathrm{L}-100)$ resulted in a reduction in the soluble sugar content compared to S plants. 


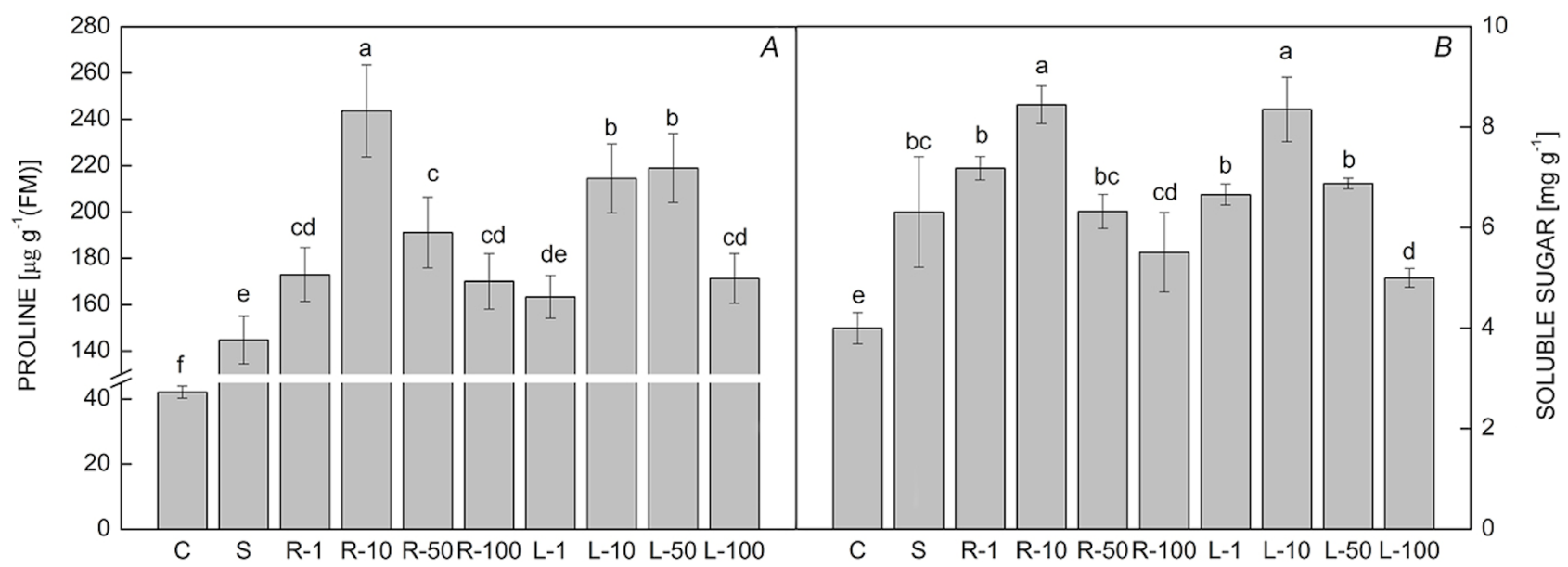

Fig. 6. Effects of the root application (R) or leaf spraying (L) with 1, 10, 50, and $100 \mu \mathrm{M}$ acetylcholine (ACh) on the proline $(A)$ and soluble sugar $(B)$ contents of 15-d-old Nicotiana benthamiana plants grown in 1/2 Hoagland solution with or without $150 \mathrm{mM} \mathrm{NaCl}$. Data are the means $\pm \mathrm{SD}, n=3$. Different letters in the same column indicate significant difference between treatments at $p \leq 0.05$ using DMRT.

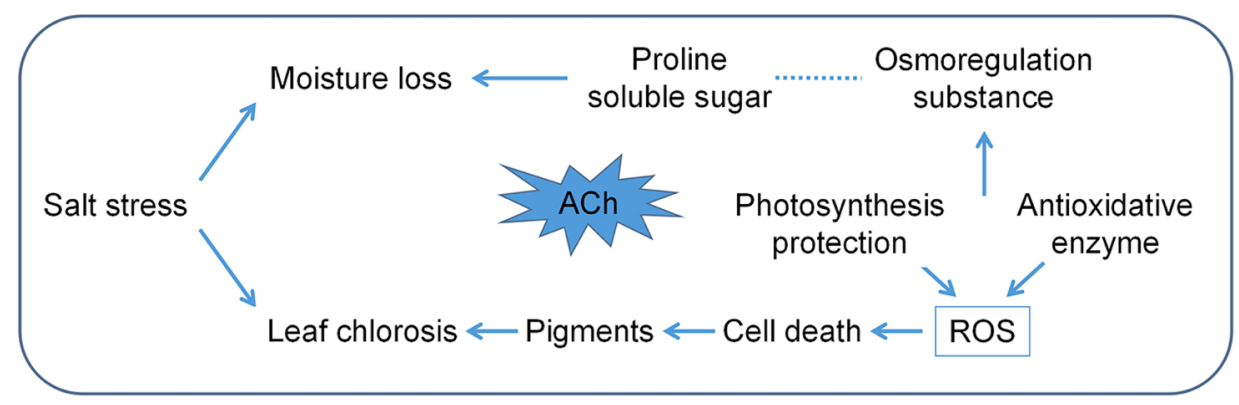

Fig. 7. A model depicting how acetylcholine (ACh) improves tolerance to salt stress. Under salinity stress, the increased photosynthetic ability contributes to suppression of ROS production, activates antioxidant enzymes which leads to reduced membrane lipid peroxidation, promotes the accumulation of key osmolytes, maintains the water status, and reduces chlorosis, thereby improving salt-stress tolerance.

Leaf relative water content (LRWC): There was a significant difference between the $\mathrm{S}$ and $\mathrm{C}$ treatments with respect to RWC of leaves (Table 1). Salinity stress significantly decreased LRWC by $26.7 \%$ but it was alleviated by ACh. The addition of $10 \mu \mathrm{M}$ ACh (R-10 and L-10) showed the greatest reversal of salt-induced decline in LRWC.

\section{Discussion}

The lack of studies on regulatory role of $\mathrm{ACh}$ in saltstressed plants: Acetylcholine (ACh) has a vital regulatory role in animals, but its role in the regulation of metabolic processes in plants has not been adequately studied (Braga et al. 2017). Numerous studies have illustrated that exogenous application of this substance could reduce the adverse effects of salt stress, which is manifested as improved gas exchange as well as biochemical responses of plants (Abbas et al. 2015, Li et al. 2017b, MatuszakSlamani et al. 2017). Therefore, the main aim of our work was to investigate whether the presence of ACh could ameliorate salt stress-induced adverse effects on Nicotiana benthamiana plants.
Effect of Chl accumulation by exogenous ACh under salt stress: The in vitro test on leaf discs was conducted to assess the extent of chlorosis in salt-stressed Nicotiana benthamiana seedlings. It is clear from the results that $10-\mu \mathrm{M}$ ACh solution was effective in alleviating the saltstress-induced chlorosis on leaves (Fig. 2). It is widely known that chlorosis can destruct Chl pigments, hinder Chl synthesis, and perturb pigment protein complex (Rasool et al. 2013, Zhao et al. 2016). To confirm such a visual observation, we assayed the total $\mathrm{Chl}$ and used SPAD instrument to verify biochemical response of Nicotiana benthamiana leaf resulting in chlorosis. In our experiment, total Chl and SPAD values were significantly depressed under salt stress and the adverse effect was caused by the $100 \mu \mathrm{M}$ ACh (both leaf and root application) (Fig. 3). Taken together, the exogenous ACh was beneficial for the stabilization of $\mathrm{Chl}$ and improvement of the photosynthetic attributes in response to salt stress. These findings would be important to further uncover physiological functions in stressed plants triggered by ACh.

Regulation of photosynthetic capacity by exogenous ACh under salt stress: Photosynthetic parameters are 
Table 1. Effects of the root application (R) or leaf spraying (L) with $1,10,50$, and $100 \mu \mathrm{M}$ acetylcholine (ACh) on the leaf relative water content (LRWC) of $15 \mathrm{~d}$ tobacco plants grown in $1 / 2$ Hoagland solution with or without $150 \mathrm{mM} \mathrm{NaCl}$. Data are the means \pm SD of three replicates. Different letters in the same column indicate significant difference between treatments at $p \leq 0.05$ using DMRT. $\mathrm{C}-$ plants grown under normal conditions for $15 \mathrm{~d}$ after supplying water through roots or as foliar spray; $\mathrm{S}$ - plants grown at $150 \mathrm{mM} \mathrm{NaCl}$ for $15 \mathrm{~d}$ after supplying water through roots or as foliar spray. $\mathrm{L}-$ plants grown at 150 $\mathrm{mM} \mathrm{NaCl}$ for $15 \mathrm{~d}$ after supplying ACh $(1,10,50$ and $100 \mu \mathrm{M}$ $\mathrm{ACh}$ ) to leaves; R - plants grown at $150 \mathrm{mM} \mathrm{NaCl}$ for $15 \mathrm{~d}$ after supplying $\mathrm{ACh}(1,10,50$ and $100 \mu \mathrm{M} \mathrm{ACh})$ to roots.

\begin{tabular}{ll}
\hline Treatment & LRWC [\%] \\
\hline C & $89.22 \pm 1.62^{\mathrm{a}}$ \\
S & $65.40 \pm 1.02^{\mathrm{d}}$ \\
R-1 & $73.43 \pm 0.77^{\mathrm{b}}$ \\
R-10 & $71.14 \pm 2.08^{\mathrm{bc}}$ \\
R-50 & $62.98 \pm 0.71^{\mathrm{d}}$ \\
R-100 & $61.97 \pm 1.42^{\mathrm{d}}$ \\
L-1 & $71.77 \pm 0.39^{\mathrm{b}}$ \\
L-10 & $74.75 \pm 3.00^{\mathrm{b}}$ \\
L-50 & $65.98 \pm 8.40^{\text {cd }}$ \\
L-100 & $63.39 \pm 2.79^{\mathrm{d}}$ \\
\hline
\end{tabular}

widely used to assess the relative impact of environmental stresses (Singh et al. 2017). Nelson et al. (2007) have reported that $P_{\mathrm{N}}$ and $g_{\mathrm{s}}$ were sensitive to saline stress. Our results showed that gas-exchange indices $\left(P_{\mathrm{N}}, g_{\mathrm{s}}, C_{\mathrm{i}}\right.$, and $E)$ of Nicotiana benthamiana seedlings were inhibited by salinity stress. Similar reports also show that stress markedly reduced gas-exchange characteristics in many plant species, such as barley (Hordeum vulgare L.) (Mahlooji et al. 2018), sunflower (Helianthus annuus L.) (Shahbaz et al. 2011), and wheat (Triticum aestivum L.) (Sikder et al. 2015). In addition, $10 \mu \mathrm{M}$ ACh solution applied to roots (R-10) or leaves (L-10), both alleviated the salt-induced damage to Nicotiana benthamiana seedlings and significantly enhanced leaf photosynthetic performance (Fig. 4). Many studies have shown that $C_{\mathrm{i}}$ decreased under different stresses, e.g., cadmium toxicity (Ali et al. 2015), water deficiency (Radwan and Fayez 2016), salinity stress (Moradi and Ismail 2007, Naeem et al. 2010), and high temperature (Wu et al. 2012). Our current results showed that there was a high linear correlation between the $P_{\mathrm{N}}$ and $g_{\mathrm{s}}$ in the leaves and both $P_{\mathrm{N}}$ and $g_{\mathrm{s}}$ significantly decreased, indicating that some stomatal closure under salt stress restricted the external $\mathrm{CO}_{2}$ from entering the leaves, thereby resulting in the reduction of $C_{\mathrm{i}}$ value.

Effect of the exogenous ACh on membrane lipid peroxidation and antioxidant enzymes under salinity stress: It is widely believed that MDA is a potential indicator of oxidative stress-induced lipid peroxidation (Hernandez et al. 2010, Xi et al. 2013, Yang and Guo 2018). In the current study, the MDA content increased dramatically under salt stress (Fig. 5A). However, the exogenously applied ACh reduced the negative effect of salt stress on MDA and the most effective concentration was $10 \mu \mathrm{M}$ (R-10 or L-10). However, oxidative damage is controlled by a defensive system composed of various antioxidant enzymes, such as SOD and POD (Hayat et al. 2012). Our results revealed that application of $10 \mu \mathrm{M} \mathrm{ACh}$ (R-10 or L-10) increased the activities of SOD and POD in leaves under salt stress, which indicated that it could strengthen the cell membranes by enhancing the activities of antioxidant enzymes under salinity stress (Fig. $5 \mathrm{~B}, \mathrm{C}$ ). The above ameliorative effects of the exogenous ACh on MDA accumulation could significantly improve water status in salt-stressed Nicotiana benthamiana seedlings (Table 1).

Effect of exogenous ACh on osmoregulation under salt stress: Osmotic stress is the main cause of salt injury due to obstruction of water uptake by roots and internal dehydration (Khan et al. 2012, Iqbal et al. 2016). In order to resist to salt stress, plant cells can effectively and quickly trigger the synthesis of osmolytes, such as proline, glycine betaine, and soluble sugars to improve the ability of plant cells to acquire water (Hu et al. 2012, Lei et al. 2016). Our results showed that proline and soluble sugar contents were enhanced by salt stress (Fig. $6 A, B$ ). Salinity stress dramatically increased the contents of proline and soluble sugars in many plants, such as wheat (Li et al. 2017b) and okra (Hibiscus esulentus L.) (Abbas et al. 2015), etc. Additionally, the higher content of proline and soluble sugars was recorded in R-10 and L-50, suggesting that these concentrations of $\mathrm{ACh}$ are more effective in promoting the accumulation of both key osmolytes. Such, the better osmoregulation imposed by optimal ACh concentration could maintain reduction of water loss in plant under salt stress (Table 1).

Conclusions: $\mathrm{ACh}$ is the established neurotransmitter widely used in human and animals, which is now being investigated as a novel inducer of plant tolerance to salt stress. This study demonstrated the alleviation of negative effects of salinity stress on Nicotiana benthamiana plants by either leaf spraying or root application of ACh. It is important to note that the most effective concentration of ACh was $10 \mu \mathrm{M}$. Under salinity stress, ACh-induced increased photosynthetic ability contributed to suppression of ROS production. It also activated antioxidant enzymes and decreased the extent of membrane lipid peroxidation. $\mathrm{ACh}$ was also effective in the upregulation of osmotic adjustment phenomenon in the Nicotiana benthamiana plants grown under saline stress. Maintenance of leaf water status and reduction of chlorosis were also the indicators of alleviating effects of ACh on salt-stressed Nicotiana benthamiana plants.

\section{References}

Abbas T., Balal R.M., Shahid M.A. et al.: Silicon-induced alleviation of $\mathrm{NaCl}$ toxicity in okra (Abelmoschus esculentus) is associated with enhanced photosynthesis, osmoprotectants and antioxidant metabolism. - Acta Physiol. Plant. 37: 6, 
2015.

Ahmad P., Abdel Latef A.A., Hashem A. et al: Nitric oxide mitigates salt stress by regulating levels of osmolytes and antioxidant enzymes in chickpea. - Front. Plant Sci. 7: 347, 2016.

Ali E., Maodzeka A., Hussain N. et al.: The alleviation of cadmium toxicity in oilseed rape (Brassica napus) by the application of salicylic acid. - Plant Growth Regul. 75: 641$655,2015$.

Ashraf M., Foolad M.R. Roles of glycine betaine and proline in improving plant abiotic stress resistance. - Environ. Exp. Bot. 59: 206-216, 2007.

Ashraf M., Harris P.J.C.: Potential biochemical indicators of salinity tolerance in plants. - Plant Sci. 166: 3-16, 2004.

Bae E.J., Lee K.S., Huh M.R., Lim C.S.: Silicon significantly alleviates the growth inhibitory effects of $\mathrm{NaCl}$ in saltsensitive 'Perfection' and 'Midnight' Kentucky bluegrass (Poa pratensis L.). - Hortic. Environ. Biote. 53: 477-483, 2012.

Bates L.S., Waldren R.P., Teare I.D.: Rapid determination of free proline for water-stress studies. - Plant Soil 39: 205-207, 1973.

Braga I., Pissolato M.D., Souza G.M.: Mitigating effects of acetylcholine supply on soybean seed germination under osmotic stress. - Braz. J. Bot. 40: 617-624, 2017.

Chaves M.M., Flexas J., Pinheiro C.: Photosynthesis under drought and salt stress: regulation mechanisms from whole plant to cell. - Ann. Bot. 103: 551-560, 2009.

Ewins A.J.: Acetylcholine, a new active principle of ergot. Biochem. J. 8: 44-49, 1914.

Feng Z.T., Deng Y.Q., Fan H. et al.: Effects of $\mathrm{NaCl}$ stress on the growth and photosynthetic characteristics of Ulmus pumila L. seedlings in sand culture. - Photosynthetica 52: 313-320, 2014.

Fluck R.A., Jaffe M.J.: The acetylcholine system in plants. - In: Smith H. (ed.): Commentaries in Plant Science. Pp. 119-136. Pergamon Press, Oxford 1976.

Gao J.F.: Experimental Guidance for Plant Physiology. Higher Education Press, Beijing 2006.

Gao Y., Lu Y., Wu M. et al:: Ability to remove $\mathrm{Na}^{+}$and retain $\mathrm{K}^{+}$correlates with salt tolerance in two maize inbred lines seedlings. - Front. Plant Sci. 7: 1716, 2016.

García A.C., Santos L.A., de Souza L.G.A. et al: Alleviation of osmotic stress deleterious effects in rice by vermicomposthumic acids involves the modulation of ROS accumulation and metabolism in roots. - J. Plant Physiol. 192: 56-63, 2016.

Hayat S., Yadav S., Wani A.S. et al.: Impact of sodium nitroprusside on nitrate reductase, proline content, and antioxidant system in tomato under salinity stress. - Hortic. Environ. Biote. 53: 362-367, 2012.

Hernandez M., Fernandez-Garcia N., Diaz-Vivancos P., Olmos E.: A different role for hydrogen peroxide and the antioxidative system under short and long salt stress in Brassica oleracea roots. - J. Exp. Bot. 61: 521-535, 2010.

Hodges D.M., Delong J.M., Forney C.F., Prange R.K.: Improving the thiobarbituric acid-reactive-substances assay for estimating lipid peroxidation in plant tissues containing anthocyanin and other interfering compounds. - Planta 207: 604-611, 1999.

Hu M., Shi Z., Zhang Z. et al.: Effects of exogenous glucose on seed germination and antioxidant capacity in wheat seedlings under salt stress. - Plant Growth Regul. 68: 177-188, 2012.

Iqbal N., Nazar R., Khan N.A.: Osmolytes and Plants Acclimation to Changing Environment: Emerging Omics Technologies. Pp. 170. Springer, New Delhi 2016.

Ismail A.M., Horie T.: Genomics, physiology, and molecular breeding approaches for improving salt tolerance. - Annu. Rev. Plant Biol. 68: 405-434, 2017.

Khan M.N., Siddiqui M.H., Mohammad F., Naeem M.: Interactive role of nitric oxide and calcium chloride in enhancing tolerance to salt stress. - Nitric Oxide 27: 210-218, 2012.

Lahive F., Hadley P., Daymond A.J.: The impact of elevated $\mathrm{CO}_{2}$, and water deficit stress on growth and photosynthesis of juvenile cacao (Theobroma cacao L.). - Photosynthetica 56: 911-920, 2018.

Lei P., Xu Z., Liang J. et al.: Poly( $\gamma$-glutamic acid) enhanced tolerance to salt stress by promoting proline accumulation in Brassica napus L. - Plant Growth Regul. 78: 233-241, 2016.

Li H., Chang J., Chen H. et al.: Exogenous melatonin confers salt stress tolerance to watermelon by improving photosynthesis and redox homeostasis. - Front. Plant Sci. 8: 295, 2017 a.

Li S., Jin H., Zhang Q.: The effect of exogenous spermidine concentration on polyamine metabolism and salt tolerance in zoysiagrass (Zoysia japonica Steud) subjected to short-term salinity stress. - Front. Plant Sci. 7: 1221, 2016.

Li Z.G., Duan X.Q., Min X., Zhou Z.H.: Methylglyoxal as a novel signal molecule induces the salt tolerance of wheat by regulating the glyoxalase system, the antioxidant system, and osmolytes. - Protoplasma 254: 1995-2006, 2017 b.

Mahlooji M., Seyed Sharifi R., Razmjoo J. et al.: Effect of salt stress on photosynthesis and physiological parameters of three contrasting barley genotypes. - Photosynthetica 56: 549-556, 2018.

Matuszak-Slamani R., Bejger R., Cieśla J. et al.: Influence of humic acid molecular fractions on growth and development of soybean seedlings under salt stress. - Plant Growth Regul. 83: 465-477, 2017.

Miller G., Suzuki N., Ciftci-Yilmaz S., Mittler R.: Reactive oxygen species homeostasis and signalling during drought and salinity stresses. - Plant Cell Environ. 33: 453-467, 2010.

Moradi F., Ismail A.M.: Responses of photosynthesis, chlorophyll fluorescence and ROS-scavenging systems to salt stress during seedling and reproductive stages in rice. - Ann. Bot. 99: 1161-1173, 2007

Munns R., Gilliham M.: Salinity tolerance of crops - what is the cost? - New Phytol. 208: 668-673, 2015.

Naeem M.S., Jin Z.L., Wan G.L. et al.: 5-Aminolevulinic acid improves photosynthetic gas exchange capacity and ion uptake under salinity stress in oilseed rape (Brassica napus L.). - Plant Soil 332: 405-415, 2010.

Nelson D.E., Repetti P.P., Adams T.R. et al.: Plant nuclear factor $\mathrm{Y}$ (NF-Y) B subunits confer drought tolerance and lead to improved corn yields on water-limited acres. - P. Natl. Acad. Sci. USA 104: 16450-16455, 2007.

Parvaiz A., Abdel Latef A.A., Hashem A. et al.: Nitric oxide mitigates salt stress by regulating levels of osmolytes and antioxidant enzymes in chickpea. - Front. Plant Sci. 7: 347, 2016.

Radwan D.E.M., Fayez K.A.: Photosynthesis, antioxidant status and gas-exchange are altered by glyphosate application in peanut leaves. - Photosynthetica 54: 307-316, 2016.

Rasool S., Ahmad A., Siddiqi T.O., Ahmad P.: Changes in growth, lipid peroxidation and some key antioxidant enzymes in chickpea genotypes under salt stress. - Acta Physiol. Plant. 35: 1039-1050, 2013.

Sagane Y., Nakagawa T., Yamamoto K. et al.: Molecular characterization of maize acetylcholinesterase: a novel enzyme family in the plant kingdom. - Plant Physiol. 138: 1359-1371, 2005.

Sarkar R.K., Mahata K.R., Singh D.P.: Differential responses of antioxidant system and photosynthetic characteristics in four rice cultivars differing in sensitivity to sodium chloride stress. 
- Acta Physiol. Plant. 35: 2915-2926, 2013.

Sastry B.V., Sadavongvivad C.: Cholinergic systems in nonnervous tissues. - Pharmacol. Rev. 30: 65-132, 1978.

Shahbaz M., Ashraf M., Akram N.A. et al.: Salt-induced modulation in growth, photosynthetic capacity, proline content and ion accumulation in sunflower (Helianthus annuus L.). - Acta Physiol. Plant. 33: 1113-1122, 2011.

Sikder S., Foulkes J., West H. et al.: Evaluation of photosynthetic potential of wheat genotypes under drought condition. Photosynthetica 53: 47-54, 2015.

Singh S.K., Reddy V.R., Fleisher D.H., Timlin D.J.: Relationship between photosynthetic pigments and chlorophyll fluorescence in soybean under varying phosphorus nutrition at ambient and elevated $\mathrm{CO}_{2}$. - Photosynthetica 55: 421-433, 2017.

Spiro R.G.: Analysis of sugars found in glycoprotein. - In: Neufeld E.S., Ginsburg V. (ed.): Methods in Enzymology, vol. VIII. Complex Carbohydrates. Pp. 3-26. Academic Press, New York 1966.

Sugiyama K., Tezuka T.: Acetylcholine promotes the emergence and elongation of lateral roots of Raphanus sativus. - Plant Signal. Behav. 6: 1545-1553, 2011.

Tretyn A., Kendrick R.E.: Acetylcholine in plants: presence, metabolism and mechanism of action. - Bot. Rev. 57: 33-73, 1991.

Wang Y., Weide R., Govers F., Bouwmeester K.: L-type lectin receptor kinases in Nicotiana benthamiana and tomato and their role in Phytophthora resistance. - J. Exp. Bot. 66: 67316743, 2015.

Wessler I., Kilbinger H., Bittinger F., Kirkpatrick C.J.: The biological role of non-neuronal acetylcholine in plants and humans. - Jpn. J. Pharmacol. 85: 2-10, 2001.
Wu X., Li X., Zha D.: Effects of cytokinin on photosynthetic gas exchange, chlorophyll fluorescence parameters and antioxidative system in seedlings of eggplant (Solanum melongena L.) under salinity stress. - Acta Physiol. Plant. 34: 2105-2114, 2012.

Xi Z.M., Wang Z.Z. Fang Y.L. et al.: Effects of 2,4-epibrassinolide on antioxidation defense and osmoregulation systems of young grapevines ( $V$. vinifera $\mathrm{L}$.) under chilling stress. - Plant Growth Regul. 71: 57-65. 2013.

Yamamoto K., Sakamoto H., Momonoki Y.S. et al.: Maize acetylcholinesterase is a positive regulator of heat tolerance in plants. - J. Plant. Physiol. 168: 1987-1992, 2011.

Yang Y., Guo Y.: Elucidating the molecular mechanisms mediating plant salt-stress responses. - New Phytol. 217: 523539, 2018.

Zhang N., Sun Q., Zhang H. et al.: Roles of melatonin in abiotic stress resistance in plants. - J. Exp. Bot. 66: 647-656, 2015.

Zhao B., Liu Z., Ata-Ul-Karim S.T. et al.: Rapid and nondestructive estimation of the nitrogen nutrition index in winter barley using chlorophyll measurements. - Field Crop Res. 185: 59-68, 2016.

Zhen X.H., Xu J.G., Shen W.J. et al.: Photosynthetic characteristics of flag leaves in rice white stripe mutant 6001 during senescence process. - Rice Sci. 21: 335-342, 2014.

Zhu J.K.: Regulation of ion homeostasis under salt stress. - Curr. Opin. Plant Biol. 6: 441-445, 2003.

Zlobin I.E., Ivanov Y.V., Kartashov A.V. et al.: Impact of weak water deficit on growth, photosynthetic primary processes and storage processes in pine and spruce seedlings. - Photosyn. Res. 139: 307-323, 2019.

(C) The authors. This is an open access article distributed under the terms of the Creative Commons BY-NC-ND Licence. 